\title{
Artículos Especiales
}

\author{
PALABRAS CON MOTIVO DE LA DISTINCIÓN \\ DE DOCTOR HONORIS CAUSA POR LA \\ UNIVERSIDAD CATÓLICA LOS ÁNGELES \\ DE CHIMBOTE
}

Claudio Rama ${ }^{l}$

Vengo aquí ante ustedes con el agradecimiento por la distinción que me otorgan y con la felicitación al proyecto que ustedes encarnan. Con el agradecimiento a la Universidad Católica Los Ángeles de Chimbote (ULADECH), a su Rector, el Ing. Dr. Julio Domínguez y a su Decano de la Facultad de Educación, el Padre Dr. Juan Rodríguez, por tener la gentileza y la deferencia que me honra de ser portador de la distinción de Doctor Honoris Causa por parte de vuestra casa de estudios y que desde ahora hasta siempre me acompañará. Pero tal distinción tiene más importancia para mí, por el valor de vuestro proyecto y vuestra misión, por lo cual me siento doblemente honrado de portar una distinción por parte de quienes se merecen al mismo tiempo el reconocimiento por la construcción de un proyecto universitario de vanguardia, de inserción social, de perfil ético y buscando la calidad y que aporta soluciones y desafíos interesantes en este nuevo mundo global y tecnológico.

Hay una pregunta que se ha constituido en un desafío permanente en la historia y que hoy tiene nuevas dimensiones. Ella se centra en el desarrollo de las ciudades pequeñas del interior. Implica la necesidad de formular políticas para impulsar las capacidades y las acciones de al interior de organizaciones

1 Economista; Master en Educación; Doctor en Educación; Doctor en Derecho. Ex -Director del Instituto Internacional de la UNESCO para la Educación Superior en América Latina y el Caribe (IESALC). Decano de la Facultad de Ciencias Empresariales de la Universidad de la Empresa (UDE); Director del Observatorio de la Educación Virtual en América Latina de Virtual Educa. 
localizadas en las ciudades pequeñas para poder desarrollar sus servicios con bajas escalas y al tiempo a responder a las tendencias a la centralización y las exigencias de calidad en la prestación de servicios. El eje de este tema radica en el estudio y la formulación de políticas para construir capital intelectual de los ciudadanos de las ciudades pequeñas sin que ellos tengan que abandonar sus territorios. En cómo pueden lograr estos habitantes en ser partes de un mundo cada vez más global, accediendo a la información y los beneficios de las aldeas globales y por ende del desarrollo social y económico y al mismo tiempo vivir en la comarca, en su contexto de identidad y de historias.

Es un tema que siempre me ha llamado la atención, en tanto yo mismo vengo de un país pequeño, altamente macrocefálico donde su capital Montevideo y su área metropolitana concentran más del 50 por ciento de la población. Veo vuestros desafíos y logros, con los ojos desde mi propio país que tiene una capital con indicadores elevados de cobertura universitaria y una desigualdad triste en el interior, y al mismo tiempo una continua migración de profesionales que se van del país en un drenaje continuo, primero a la capital y muchos veces en un tránsito al extranjero. Es un desafío dado por la problemática de cómo ser parte de una sociedad global con igualdad de accesos y posibilidades todos los ciudadanos del país más allá de donde están radicados, y como se puede ser parte de un mundo global y aportar y beneficiarse de esa interacción.

Es necesario recordar cómo eran los mundos universitarios hace pocos años. En ellos dominaban modelos educativos presenciales donde las instituciones universitarias estaban localizadas en las capitales de los países o en las grandes ciudades y donde en el interior profundo se carecía de acceso a los servicios universitarios. Apenas unos pocos, que provenían de las elites económicas y sociales se podrían trasladar a estudiar en las capitales. Había una altísima desigualdad en las oportunidades de las personas. Y aún aquellos que accedían a migrar para estudiar impulsaban una fuga permanente de jóvenes, un drenaje continuo de personas cuya construcción de capital humano era muy selectiva. Tal fuga era permanente ya que muy pocos volvían a sus ciudades de origen. La literatura de los años 50 y 60 en toda América está llena de estas narraciones y cuentos, de estas historias de jóvenes que emigraron a vivir en pensiones, a sorprenderse de las ciudades, a conocer nuevas experiencias, a ser partícipes de movimientos políticos, culturales y sociales que impulsaron cambios en nuestras tradicionales sociedades, y que también mostraron el desarraigo y la perdida de capacidades de las regiones ya que en su mayoría ellos no volvieron a sus 
lugares de origen. La mayor parte se radicó en esas capitales o grandes ciudades o inclusive continuó su migración hacia el extranjero y pocas veces volvieron a sus ciudades, desgarrando familias y tradiciones. No sólo para esas ciudades fue una perdida de jóvenes, sino que también se expresó en la ausencia de recursos humanos especializados a futuro. Ello reprodujo un ciclo de pobreza y marginamiento ante la carencia de recursos humanos especializados. Tal dinámica ha reforzado y reproducido el ciclo de desigualdad que caracteriza a nuestra región dado por la desigualdad geográfica marcada por la concentración de profesionales y especialistas en algunas ciudades y su ausencia en otras. Los desequilibrios y las desigualdades de capital humano son la base de las desigualdades sociales y regionales.

Las clases medias en nuestra región son los factores fundamentales de la equidad, los centros de la democratización social, los escalones y determinantes de la movilidad social, y ellas cada vez más están asociadas al capital humano adquirido por técnicos y profesionales a través de la formación terciaria. En dicho contexto, las brechas de diferencias regionales se amplían cuando apenas unos pocos pueden asumir los costos de estudiar fuera y además muy pocos de ellos regresan.

Hace ya más de 150 años, el Libertador Simón Bolívar planteó la necesidad de regionalizar la elitista universidad de entonces. Recuerdo ahora haber estado en la Universidad Nacional de Trujillo, aquí cerca de Chimbote, y haber visto el impacto que en la ciudad y en dicha sociedad significó ese decreto del Libertador en la perspectiva de los años. Pero ver el impacto en Trujillo y su estructura social es también ver la ausencia de estos impactos en las decenas de ciudades y pueblos del interior de los países de la América profunda que carecieron de estos elitistas servicios universitarios. Había una lógica explicación. No era posible soñar con una universidad con buenos profesores y bibliotecas, con diversidad de programas y niveles, con escalas eficientes educativas y sociales, en cada ciudad de las miles que cada vez más traviesan nuestra región. Su imposibilidad radicaba en una concepción basada en modelos educativos presenciales, que no ha permitido por décadas dar solución a las necesidades de las personas de estudiar y detener el continuo flujo y fuga de jóvenes.

Estamos a favor de la libertad de las personas de escoger su lugar en el mundo, de movilizarse a donde más le convenga y desea, a impulsar la movilidad y el crecimiento individual. Pero ello sólo es posible en igualdad de condiciones. No es libre quien decide irse a estudiar o trabajar afuera por no tener 
oportunidades en igualdad de condiciones donde reside, sino que al contrario para acceder a esos instrumentos de movilidad social, de crecimiento y de desarrollo individual, debe también abandonar su territorio, su familia y tradiciones. Es un complejo dilema para muchas personas y que de hecho imposibilita que haya una libertad efectiva. Libertad es cuando se decide en igualdad de condiciones, no donde se imponen caminos únicos para poder construir las capacidades personales. Cada vez más la educación a distancia y especialmente la educación virtual supera completamente esas disyuntivas de migrar o carecer de capital humano. Sin embargo, al igual que antes, hay algunos que restringen esas posibilidades de libertades por parte de las personas y de las organizaciones. En la mayor parte de América Latina no se aprovechó las potencialidades de la educación a distancia que ya tiene decenas de años en el mundo. La tradición, las ideologías, los paradigmas educativos y el desconocimiento, impusieron una concepción errónea de la calidad asociada a la presencialidad. Muchas veces fueron corporaciones que no permitieron democratizar los accesos a través de estas nuevas modalidades por no tener las capacidades ni la voluntad. Todo ello ha frustrado la posibilidad de miles de personas en nuestra región de desarrollar sus posibilidades educativas y de acceso a una vida mejor. Estos modelos educativos hace decenas de años que pudieran haberse impuesto; hace decenas de años que hubieran permitido a muchas personas superar el ciclo de la pobreza dado por bajo capital humano y bajos salarios; hace decenas de años que hubieran podido contribuir a aumentar la productividad y conformar cambios en las estructuras sociales y económicas de sus territorios, facilitando a su vez la creación de capas media y mecanismos de movilidad social. Hubiera permitido en las ciudades y pueblos del interior de nuestros países, que miles de personas desarrollaran nuevos caminos de vida. Ha sido ésta una dictadura de las normas esclerosadas y las concepciones atrasadas que al tiempo no ha permitido ejercer la libertad a través permitir expandir el acceso a la educación superior y con ello impulsar la democratización social que implica la construcción de capital humano de los estudios universitarios para las personas.

Aún quedan focos resistentes a estos modelos universitarios, focos ideológicos que no comprenden la educación como un proceso de autoaprendizaje guiado, que conciben una educación catedrática, encerrada en un aula, libresca, de elites, de estudiantes de familias con recursos, de modelos presenciales y burocráticos. La educación a distancia en sus diversas modalidades, en su significado de otorgar mayor impulso al esfuerzo personal, al permitir el acceso de miles de personas limitadas a la movilidad, es hoy una de las puntas de lanza en 
la democratización social del continente a través de la construcción de capital humano y con ello de mejores salarios y movilidad social.

Por ello, el ser distinguido por quienes como ustedes están dedicados a esta tarea de construir estos caminos del porvenir a través de la democratización de la educación a través la construcción de capital humano a distancia con calidad, me honra, me llena de oxígeno, de esperanza y me refuerza en mis valores y en la esperanza de una educación para todas las personas, más allá de raza, credo, sexo, ideología, condición social o localización geográfica, y también con ello ayudarnos a todos al avanzar a construir sociedades del conocimiento y del desarrollo.

Chimbote, Perú, 9 de octubre del 2012. 